\title{
Que violência é essa, mulher, em tua casa, em tempos de Pandemia? A aplicação da lei $n^{\circ}$. 11.340/06 Maria da Penha em Maceió-AL
}

\section{What violence is this, woman, in your home, in times of Pandemic? The application of law no. 11.340 / 06 Maria da Penha in Maceió-AL}

\begin{abstract}
1) ORCID nº https://orcid.org/0000-0002-5035-7126, professor da Educação Básica e do Ensino Superior; Pesquisador do Grupo de Gestão e Avaliação Educacional (GAE/UFAL), do Grupo de Pesquisa e Estudos da Ciência Conjunta Penal (GECCOPE/UNEAL), do Grupo de Estudos Avançados pelo Instituto Brasileiro de Ciências Criminais (IBCCRIM/CESMAC) e membro da Sociedade Brasileira para o Progresso da Ciência (SBPC), sócio da Associação Nacional de Política e Administração da Educação (ANPAE) e diretor da seção ANPAE/AL; Doutorando em Educação e mestre em Ensino pela Universidade Federal de Alagoas (UFAL) e estudante do Curso de Bacharelado em Direito pela Universidade Estadual de Alagoas (UNEAL) - Campus VI; Maceió, Alagoas; Brasil. E-mail: javansami@hotmail.com

(2) ORCID no https://orcid.org/0000-0001-9907-1244, professora, atua na Educação Básica; Possui formação em Letras-Espanhol pela Universidade Federal de Alagoas (UFAL); Graduanda do Curso de Bacharelado em Direito pela Universidade Estadual de Alagoas (UNEAL) - Campus VI, membro do Grupo de Estudos da Ciência Conjunta Penal (GECCOPE) e do Instituto Brasileiro de Ciências Criminais (IBCCRIM/UNIT); Maceió, Alagoas; Brasil. E-mail: claysevieira@hotmail.com

${ }^{(3)}$ ORCID nº https://orcid.org/0000-0002-7866-8006, Professor Assistente "B" na Universidade Estadual de Alagoas (UNEAL) no curso de graduação em Direito. Professor convidado dos cursos de Pós-graduação lato sensu em Direito, pela Faculdade de Direito do Centro Universitário CESMAC, pela Faculdade Estácio de Sá (Faculdade de Alagoas - FAL), pela Faculdade de Direito FAMA e pela Faculdade Raimundo Marinho (FRM); Por meio do CNPq é criador e líder do GECCOPE e GEDD; respectivamente, Grupo de Estudos da Ciência Conjunta Penal e do Grupo de Estudos em Gênero, Diversidades e Direitos Humanos; Graduado em Direito pelo CESMAC. Mestre em Direito pela Universidade Federal de Pernambuco (UFPE); Doutorando em Educação pelo Programa de Pós-graduação em Educação da Universidade Federal do Rio Grande do Sul (PPGEdu/ UFRGS); Pós-graduado pela Escola Superior da Magistratura de Alagoas (ESMAL); Pós-graduado pela Escola Superior do Ministério Público de Alagoas (ESMPAL) e Centro Universitário do CESMAC; Maceió, Alagoas; Brasil. E-mail: lucio.izidro@uneal.edu.br
\end{abstract}

Todo o conteúdo expresso neste artigo é de inteira responsabilidade dos seus autores.

RESUMO: O presente artigo expõe a violência doméstica contra a mulher em tempos de Pandemia do COVID-19 para realizar a análise das interfaces conjunturais do gênero na atualidade, procurando identificar quais são as implicações na tomada da opção pela Lei 11.340/06 (Lei Maria da Penha), quando utilizado no sistema judiciário criminal como disparador na correção de conflitos violentos contra a mulher. De natureza quali-quanti, partiremos do estudo bibliográfico, da análise documental e de conteúdo como abordagens metodológicas e demais técnicas para a coleta de dados. Muitos estudos contêm as inúmeras faces da defesa da violência contra a mulher FERNANDES (2012); SILVA (2009); ZIZEK (2008) na realidade doméstica afirmando que, as normas constitucionais devem estruturar-se e ordenar-se de tal forma que possibilitem a pronta identificação da posição jurídica em que investem os jurisdicionados BARROSO (2009); PORTO (2008); SILVA (2009), entre outros, e tais posições devem ser resguardadas por instrumentos de tutela adequados, aptos à sua realização prática. Concernente às técnicas e instrumentos da coleta de dados, verificamos inclusive que a pesquisa contribuiu com a análise e compreensão das interfaces da violência contra a mulher no município de Maceió-AL, uma vez que os dados do relatório da Secretaria de Estado da Segurança Pública (SSP-AL) mostraram ocorrer 141 (cento e quarenta e um) casos de violência contra a mulher no período do carnaval 2020, em Alagoas. Já em Maceió, sem uma reflexão mais aprofundada dos porquês nos elevados índices de violência doméstica contra mulheres em tempos de COVID-19, devido ao processo contínuo da pesquisa, os dados da Patrulha Maria da Penha (2020) revelam que na cidade o aumento foi de 146\% (cento e quarenta e seis por cento) de janeiro a 26 de maio de 2020. Assim sendo, destacando o dado em comparação com o mesmo período do ano anterior.

PALAVRAS-CHAVE: Pandemia do Coronavírus, Violência Doméstica, Violência contra a Mulher.

ABSTRACT: This article exposes domestic violence against women in times of Pandemic COVID-19 to carry out the analysis of the conjunctural interfaces of gender today, seeking to identify what are the implications in taking the option for Law $11.340 / 06$ (Law Maria da Penha), when used in the criminal justice system as a trigger in the correction of violent conflicts against women. Of a quali-quanti nature, we will start from the bibliographic study, from the documentary and content analysis as methodological approaches and other techniques for data collection. Many studies contain the many faces of the defense of violence against women FERNANDES (2012); SILVA (2009); ZIZEK (2008) in the domestic reality, stating that the constitutional norms must be structured and ordered in such a way as to enable the prompt identification of the legal position in which the jurisdicted BARROSO (2009) invest; PORTO (2008); SILVA (2009), among others, and such positions must be safeguarded by appropriate tutelage instruments, suitable for their practical realization. Concerning the techniques and instruments of data collection, we also verified that the research contributed to the analysis and understanding of the interfaces of violence against women in the city of Maceió-AL, since the data from the report of the State Secretariat of Public Security (SSP-AL) showed 14.1 (one hundred and forty-one) cases of violence against women during Carnival 2020, in Alagoas. In Maceió, however, without further reflection on the reasons for the high rates of domestic violence against women in times of COVID-19, due to the continuous research process, data from Patrulha Maria da Penha (2020) reveal that in the city the increase was from $146 \%$ (one hundred and forty-six percent) from January to May 26, 2020. Therefore, highlighting the data in comparison with the same period of the previous year. KEYWORDS: Coronavirus pandemic, Domestic Violence. Violence against Women. 


\section{INTRODUÇÃO}

No final de 2019, o mundo inteiro se deparou com o surgimento de uma doença viral advinda da cidade de Wuhan, na China. Essa doença, recebeu da Organização Mundial da Saúde (OMS) o nome de Covid-19, que se refere ao ano de surgimento do vírus, 2019, sendo popularmente conhecida como Coronavírus - o mais alto nível de alerta da Organização -, conforme previsto no Regulamento Sanitário Internacional, sendo, em 11 de março de 2020, caracterizada como uma pandemia mundial, com casos de infecção e mortes registrados em mais de 185 países, tornando assim, uma ameaça à saúde humana e afetando a dinâmica socioeconômica do planeta.

O mundo acompanha dia após dia a crescente vertiginosa dos casos de pessoas contaminadas e mortes por Covid-19. Em meio a tantas incertezas o método para contenção da propagação do vírus orientado pela Organização Mundial de Saúde (OMS) mais seguro é o isolamento social. Porém, surgem problemáticas em meio a esse cenário, os comportamentos sociais, dentre eles, um vem chamando a atenção, o aumento dos índices de violência doméstica e de feminicídio.

Pode-se aferir esse ciclo de violências as tensões emocionais vividas pelos agressores, esta fase é observada pelo desrespeito, impaciência, irritabilidade e passagens de fúria por parte do agressor diante de situações frívolas, insignificante. O maior problema é a vítima se acostumar com a situação, muitas não se percebem no contexto de violência, pois acontece de forma gradual, como também é comum a vítima se minimizar com o comportamento do parceiro e em muitos casos sente-se como se tivesse contribuído para a violência.

Com o crescente número da violência doméstica em Maceió, a Ordem dos Advogados do Brasil Seccional Alagoas (OAB-AL) solicitou ao Tribunal de Justiça de Alagoas (TJAL) que emitisse uma recomendação para que os juízes prorroguem medidas protetivas de urgência às mulheres em situação de violência doméstica. Foi ao observar essa situação que o presente artigo incidiu em estudar os alarmantes números expressos pela mídia televisiva e noticiada pelos jornais de larga escala no Estado de Alagoas. Sendo assim, justificando a necessidade de investigação dos porquês do aumento tão significativo da violência doméstica em tempos de COVID-19 e como o dispositivo da Lei Maria da Penha (Lei n ${ }^{\circ} 11.340$ ) assegurou o combate desta violação. 
O artigo é fruto de um projeto de pesquisa em andamento, intitulado: "VIOLÊNCIA DOMÉSTICA CONTRA A MULHER EM TEMPOS DE PANDEMIA: Uma Análise das Interfaces Conjunturais do Gênero na Atualidade e no Pós-Pandemia (2020-202 1)”, e expõe a violência doméstica contra a mulher em tempos de Pandemia do COVID-19 para realizar uma análise das interfaces conjunturais do gênero na atualidade, procurando identificar quais são as implicações na tomada da opção pela Lei 11.340/06 (Lei Maria da Penha), quando utilizado no sistema judiciário criminal como disparador na correção de conflitos violentos contra a mulher.

De natureza quali-quanti, partimos do estudo bibliográfico, da análise documental e de conteúdo como abordagens metodológicas e demais técnicas para a coleta de dados. Muitos estudos contêm as inúmeras faces da defesa da violência contra a mulher FERNANDES (2012); SILVA (2009); ZIZEK (2008) na realidade doméstica afirmando que, as normas constitucionais devem estruturar-se e ordenar-se de tal forma que possibilitem a pronta identificação da posição jurídica em que investem os jurisdicionados BARROSO (2009); PORTO (2008); SILVA (2009), entre outros, e tais posições devem ser resguardadas por instrumentos de tutela adequados, aptos à sua realização prática.

Embora a Lei de $n^{0} 11.340 / 2006$ - Lei Maria da Penha - não tenha prevenido um rito novo para abarcar as necessidades das mulheres que sofrem violência doméstica, ela conseguiu tipificar condutas, estabelecer regras atemporais e traçou as diretrizes para o processo. Ainda assim, conseguiu modificar aspectos que vão desde os procedimentos à novas configurações da atuação dos advogados e dos demais sujeitos envolvidos na relação jurídica processual.

Assim, contextualizar a Pandemia de Coronavírus, Violência Doméstica contra a mulher e a Lei Maria da Penha é trazer luz a administração dos conflitos por ela compreendidos nos Juizados Especiais Criminais, que neste sentido, deveriam analisar o aumento das agressões físicas praticadas contra as mulheres, em que se pese até verificar os silenciamentos dos casos em seus lares como forma de vergonha, medo, trauma, dores, angústias, entre outros sinais emocionais.

Portanto, nesta breve introdução que cerca o presente estudo, conseguimos optar pela originalidade da pesquisa no campo das Ciências Criminais em Maceió, e tivemos um olhar voltado a relevância de cunho social e jurídica, uma vez que trata da efetividade da Lei $\mathrm{n}^{\circ}$ 11.340/2006, conhecida como Lei Maria da Penha, para o 
enfrentamento da violência doméstica e familiar contra a mulher. Sendo assim, para fins de estudos, pesquisas e produção de artigos, é um fenômeno complexo, que envolve exterioridades de culturais, história, aspecos familiares, e principalmente sociais, enraizados no imaginário coletivo da sociedade com traços e comportamentos machistas, na submissão da mulher, decorrente de um padrão comportamental descabido e desenvolvido numa pedagogia viral. Isso porque, com o aumento considerável da violência, talvez estejam aprendendo ser mais terríveis com as mulheres em casa. Mulher, não se cala!

\section{REFERENCIAL TEÓRICO}

A violência contra a mulher tem suas raízes no modelo de sociedade patriarcal e a ideia de inferioridade e submissão feminina. Neste entendimento, nos aponta Lerner (2019) que a dominação masculina remonta principalmente o período dos Estados Arcaicos, no sentido de que houve um processo de construção da "coisificação" da mulher, e eram tratadas mais como coisas do que sujeitos de dignidade humana.

Diante dessa perspectiva, tal subordinação contaminou diversas instituições sociais, principalmente no âmbito jurídico, sendo legitimada inclusive pelos primeiros Códigos Penais. Dessa maneira, a cooperação da mulher ao sistema segue uma lógica de controle sexual, econômico e social garantida por meio da força. Panorama esse, que ainda deixa resquícios na atual sociedade brasileira, dada a persistência da violência doméstica contra a mulher.

Além disso, ressalta Saffioti (2011), é uma estrutura de poder baseada tanto na ideologia quanto na violência, que ignora fronteiras de classe social, e engloba não só a integridade física feminina, mas significa uma ruptura de integridades: física, psicológica, sexual e moral. Sendo assim, a referida autora assinala, embora existam instrumentos jurídicos de proteção a mulher no Brasil, como por exemplo a Lei Maria da Penha, os profissionais ligados a essas atividades não possuem qualificação adequada no conhecimento da relações de gênero, algo essencial para que a prestação do serviço de proteção seja de um todo homogêneo, de boa qualidade e portanto, eficaz. 
É por isso que deve-se reforçar a aplicabilidade da Lei Maria da Penha como disparador que dispõe preliminarmente sobre a criação de mecanismos para coibir e prevenir a violência doméstica e familiar contra a mulher, e que é fundamentada constitucionalmente nos termos encontrados no $\S 8^{\circ}$ do artigo 226 da Constituição Federal como se depreende o excerto: “O Estado assegurará a assistência à família na pessoa de cada um dos que a integram, criando mecanismos para coibir a violência no âmbito de suas relações.” (BRASIL, 1998).

Para Zizek (2008) a violência objetiva é uma violência invisível, uma vez que é precisamente ela que sustenta a normalidade do nível zero contra a qual percebemos algo como subjetivamente violento. Assim, nota-se que há uma necessidade de tornar-se visível uma ação de violência se quisermos elucidar manifestações "inconcludentes" que eclodirá em uma violência subjetiva.

A lei 11. 340/2006 no art. $7^{\circ}$ parágrafo II declara que "[...] a violência psicológica, entendida como qualquer conduta que the cause dano emocional e diminuição da autoestima ou que lhe prejudique e perturbe o pleno desenvolvimento [...]”.(BRASIL, p 2018).

Portanto, o artigo $7^{\circ}$, parágrafo II da Lei 11.340, de 07 de agosto de 2006 corrobora e aponta que os comportamentos antes tidos como "normais", com a vigência desta lei, configuram-se em crime, tratando-se inclusive, de uma violência objetiva, invisível, pois é sustentada por uma normalidade. Essa questão é tão imperceptível para algumas, que muitas mulheres não só sofrem a agressão, como também, a mantém.

\section{PROCEDIMENTO METODOLÓGICO}

Procurando identificar quais são as implicações na tomada da opção pela Lei 11.340/06 (Lei Maria da Penha), quando utilizado no sistema judiciário criminal como disparador na correção de conflitos violentos contra a mulher, buscamos assim, com o estudo bibliográfico e a análise de conteúdo que compõem as abordagens metodológicas deste artigo, num primeiro momento, iniciar as leituras básicas sobre as questões da Lei 11.340/06 (Lei Maria da Penha). 
De natureza quali-quanti, partiremos do estudo bibliográfico, da análise documental e de conteúdo como abordagens metodológicas e demais técnicas para a coleta de dados. Muitos estudos contêm as inúmeras faces da defesa da violência contra a mulher FERNANDES (2012); SILVA (2009); ZIZEK (2008) na realidade doméstica afirmando que, as normas constitucionais devem estruturar-se e ordenar-se de tal forma que possibilitem a pronta identificação da posição jurídica em que investem os jurisdicionados BARROSO (2009); PORTO (2008); SILVA (2009), entre outros, e tais posições devem ser resguardadas por instrumentos de tutela adequados, aptos à sua realização prática.

Como primeira etapa da metodologia da pesquisa, conseguimos mapear e escolher os bairros que atenderam aos critérios definidos, a saber: bairros com o maior número de habitantes, com altos índices de analfabetismo; com altos índices de criminalidade; maior número de mulheres desempregadas; e, maior número de donas de casas sem emprego e renda. Sendo assim, alguns bairros de Maceió se apresentam como mais violentos, segundo dados da Secretaria de Segurança Pública (2019) em consonância com os critérios estabelecidos. Contudo, fugiu do nosso crivo algumas variações para essas posições entre os bairros. Dentre eles, se destacam a causa do envolvimento das mulheres na seara do tráfico de drogas, pois as facções criminosas entre os bairros do Benedito Bentes, da Cidade Universitária, do Jacintinho, do Clima Bom, do Tabuleiro do Martins, do Vergel do Lago e da Levada, disputam o controle do tráfico de drogas na capital alagoana.

Concernente às técnicas e instrumentos da coleta de dados, verificamos inclusive que a pesquisa contribuiu com a análise e compreensão das interfaces da violência contra a mulher no município de Maceió-AL, uma vez que os dados do relatório da Secretaria de Estado da Segurança Pública (SSP-AL) mostraram ocorrer 141 (cento e quarenta e um) casos de violência contra a mulher no período do carnaval 2020, em Alagoas. Corroborando com a afirmação de que a "mulher nas relações de gênero com o mundo do trabalho ainda são tratadas como sujeitos "secundários" da cadeia de emprego e renda”. (PENHA, 2012, p. 78).

Ressaltamos que para as demais fases metodológicas do projeto, uma vez que muitos aspectos da pesquisa não poderão ser esclarecidos apenas com a análise documental, buscar-se-á o aprofundamento de demais pontos por meio da aplicação de questionário e a técnica da entrevista, a qual se configura como um ótimo recurso para a 
compreensão das contradições e sutilezas presentes na distância entre o discurso oficial e a realidade apresentada pelos dados qualitativos analisados.

\section{RESULTADOS E DISCUSSÃO}

Para além dos resultados com a coleta dos dados, o aprofundamento teórico se fortaleceu e se fez necessário para o cumprimento do tripé acadêmico tanto na Universidade Estadual de Alagoas (UNEAL) quanto no Centro Universitário de Maceió (CESMAC), os quais se vinculam o Ensino, a Pesquisa e a Extensão. Neste sentido, os estudos realizados no Grupo de Estudos da Ciência Conjunta Penal (GECCOPE/UNEAL) e do Grupo de Estudos Avançados (GEA/CESMAC) foram cruciais para os fins de apropriação teórica e multidisciplinar, com produção coletiva e individual de artigos científicos com a finalidade de publicação acadêmica nos seus mais variados formatos e apresentações.

Concernente às técnicas e instrumentos da coleta de dados, verificamos inclusive que a pesquisa contribuiu com a análise e compreensão das interfaces da violência contra a mulher no município de Maceió-AL, uma vez que os dados do relatório da Secretaria de Estado da Segurança Pública (SSP-AL) mostraram ocorrer 141 (cento e quarenta e um) casos de violência contra a mulher no período do carnaval 2020, em Alagoas.

Já em Maceió, sem uma reflexão mais aprofundada dos porquês nos elevados índices de violência doméstica contra mulheres em tempos de COVID-19, devido ao processo contínuo da pesquisa, os dados da Patrulha Maria da Penha (2020) revelam que na cidade o aumento foi de $146 \%$ (cento e quarenta e seis por cento) de janeiro a 26 de maio de 2020. Assim sendo, destacando o dado em comparação com o mesmo período do ano anterior.

Percebemos que com a pandemia do COVID-19 e o decreto de isolamento social em vários cidades de Alagoas, as mulheres estão passando mais tempo juntas aos seus cônjuges, o que de alguma forma nos levou a compreensão de que ocasionam desavença, discórdia, bigas e discussões. Neste sentido, elevando-se assim, o maior número de casos de violência contra a mulher em Maceió no referido recorte temporal da Pandemia do COVID-19. 
De acordo com os dados coletados, em Maceió, as mulheres devem seguir um procedimento de denúncia, quando vítima de qualquer violência por seus maridos: "formaliza a denúncia na delegacia especializada e, após o inquérito ser concluído, o assunto é tratado no juizado”. (ALAGOAS, 2020). Só depois de um atendimento judiciário é que a vítima recebe visitas da Patrulha Maria da Penha.

Portanto, destacamos que os dados ainda revelam mais os números de vítimas neste ano de 2020 com a Pandemia do COVID-19, pois de janeiro do referido ano até o dia 26 (vinte e seis) de maio já foram vítimas assistidas pela Patrulha Maria da Penha, aproximadamente 148 (cento e quarenta e oito) novas mulheres.

Temos ainda o número de 1.196 (mil cento e noventa e seis) casos de visitas fiscalizatórias e 21 (vinte e uma) prisões aos agressores dessas vítimas, o que ocorreu ainda com 12 (doze) delas no período da quarentena.

Tratando ainda sobre a violência doméstica contra a mulher, percebe-se que ela passa a ser considerada como uma ação de transgressão a partir do momento em que é qualificada e codificada em uma esfera social, dentre as suas diversas manifestações, que para Laupoujeade (2015, p. 56) a "violência não existe". A violência sempre qualificada, nunca qualquer, sempre já tomada na percepção de um campo social que a codifica ou a qualifica, mas que sobretudo a distribui. Nesse sentido, as definições da violência são sempre já políticas e estratégicas.

Para tanto, desde o início da pesquisa, verificamos por meio da Patrulha Maria da Penha (2020) que já foram encaminhadas 377 (trezentos e setenta e sete) mulheres para o atendimento pelo programa de combate a violência doméstica contra a mulher. Ressaltamos que dessas, 174 (cento e setenta e quatro) mulheres, há época de maio, encontravam-se em estado de acompanhamento e 203 (duzentos e três) já tiveram suas medidas policiais e ajuizadas encerradas.

Diante dos dados revelados na pesquisa, destaca-se o entrelaçar do estudo com o seu contexto de forma palpável, quando versamos sobre a realidade das vítimas, afirmando inclusive, que é importante observar quando a violência doméstica cresce no/e devido ao aumento do convívio e, consequentemente, das tensões em casa. Isso porque, em tempos de quarentena, a conjuntura socioeconômica atual tende a intensificála. Somado a isso, percebemos por meio de uma pesquisa paralela, da qual a Maria da Penha (2012, p.39) afirma em sua autobiografia quando o assunto é cárcere privado e relata: "sentir-me prisioneira em meu próprio lar, tendo minhas atitudes tolhidas e 
vendo-me sob o total arbítrio do próprio marido, era não somente terrível de aceitar, como também agrava a insuportável sensação de impotência”, de acordo com a citação a autora compartilha de forma única sua história de vida, esta que é tão particular e ao mesmo tempo tão comum à de tantas mulheres que levam no corpo e na alma as marcas visíveis e invisíveis da violência.

Há variados tipos de violências, algumas perceptíveis, outras não, como também, pode-se afirmar que essas situações não têm um lugar específico, ocorrem em diversos espaços sociais, profissionais, educacionais, religiosos, familiares, ambientes que envolvem pessoas. Laupoujeade (2015) diz que todos sabemos que a violência circula por todo o campo social sob as mais variadas formas, às vezes direta e explícita, outras vezes indireta, encoberta, implícita e sorrateira, às vezes física, outras vezes mental. Eis a questão, como então perceber que nas situações sorrateiras a vítima está sofrendo uma agressão de teor psicológico?

É por isso que deve-se reforçar a aplicabilidade da Lei Maria da Penha como disparador que dispõe preliminarmente sobre a criação de mecanismos para coibir e prevenir a violência doméstica e familiar contra a mulher, e que é fundamentada constitucionalmente nos termos encontrados no $\$ 8^{\circ}$ do artigo 226 da Constituição Federal como se depreende o excerto: "O Estado assegurará a assistência à família na pessoa de cada um dos que a integram, criando mecanismos para coibir a violência no âmbito de suas relações.” (BRASIL, 1998).

A lei é clara e imperativa ao tocante da segurança e assistência que deve ser prestada por parte do Estado, tendo o compromisso Constitucional de não se omitir em relação a violência doméstica que se alastra no seio familiar.

Neste diapasão entre a Lei Maria da Penha e a violência doméstica contra a mulher, o teórico Lima (2020) narra com expresso detalhe que o esposo da Maria da Penha tentou assassiná-la por mais de uma vez, sendo a primeira tentativa em 29 de maio de 1983. Marcos, esposo de Maria da Penha, atirou nas costas dela, atingindo a coluna da vítima, e deixando-a paraplégica. Dissimulador, alegou que foi um assalto e que os ladrões fugiram pela janela. Maria então, ficou internada 4 meses e posteriormente retornou ao lar, aponta Lima (2020). A próxima ação de Marco para matar sua esposa foi uma descarga elétrica enquanto Maria da Penha estava tomando banho, empurrando a cadeira de rodas e tentando eletrocutá-la. No ano de 1984, especificamente em 28 de setembro, o agressor foi denunciado. Porém, devido a lentidão 
do processo e por inúmeros recursos o marido só foi preso em 2002, e por conta dessa lentidão, numa grave violação de sua dignidade humana foi necessário acionar à Comissão Internacional de Direitos Humanos. (LIMA, 2020).

Para Zizek (2008) a violência objetiva é uma violência invisível, uma vez que é precisamente ela que sustenta a normalidade do nível zero contra a qual percebemos algo como subjetivamente violento. Assim, nota-se que há uma necessidade de tornar-se visível uma ação de violência se quisermos elucidar manifestações "inconcludentes" que eclodirá em uma violência subjetiva.

A lei $11.340 / 2006$ no art. $7^{\circ}$ parágrafo II declara que:

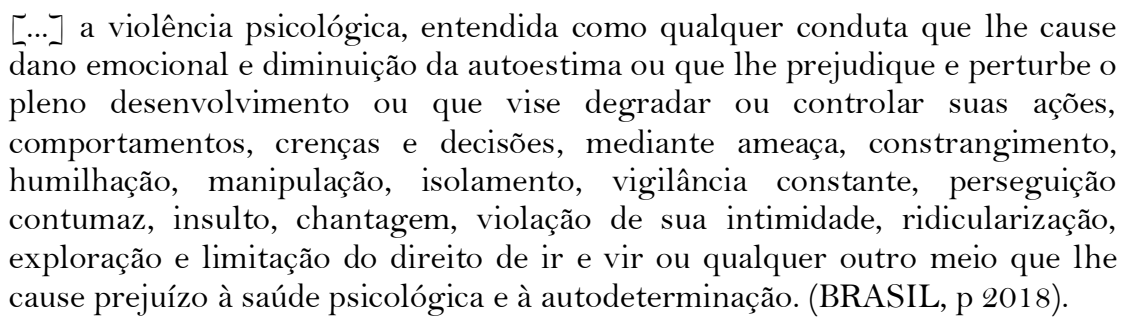

Portanto, o artigo $7^{\circ}$, parágrafo II da Lei 11.340, de 07 de agosto de 2006 corrobora e aponta que os comportamentos antes tidos como "normais", com a vigência desta lei, configuram-se em crime, tratando-se inclusive, de uma violência objetiva, invisível, pois é sustentada por uma normalidade, e muitas mulheres convivem com agressores em potencial, que usam de ações para manipular suas emoções, onde muitas mulheres não percebem que estão inseridas neste contexto de violência. Essa questão é tão imperceptível para algumas, que muitas mulheres não só sofrem a agressão, como também, a mantém. Reafirma-se e reforça ser então, no micromarchismo, o exemplo contundente de que mantemos tênue ações que conserva a mulher em uma conjuntura de inferioridade nos vários espaços sociais no quais elas estão inseridas. Sendo em seu lar a maior preocupação desta pesquisa em tempos de Covid-19, na cidade de Maceió-AL.

A temática da violência doméstica contra a mulher é urgente. Esta pauta também já foi tema de discussão pelo Tribunal de Justiça de Alagoas, pois apontou que entre os meses de março e junho do ano de 2019 foram concedidas 342 medidas protetivas a mulheres. (GAZETA DE ALAGOAS, 2020). No tocante ao ano de 2020, logo nos quatro primeiros meses em relação ao ano de 2019, os casos sofreram um aumento considerável de 310 (trezentos e dez) vítimas. 
Destacamos que na capital de Maceió, as mulheres estão garantidas de sua proteção pela Lei Maria da Penha, pois serve diretamente para afastar e proteger as vítimas dos agressores. Segundo relato de José Miranda, juiz auxiliar do Juizado da Mulher da Capital, em entrevista a Gazeta de Alagoas (2020), ele diz que:

\begin{abstract}
"O aumento do número de casos na capital é uma coisa que tem sido constante. É claro que agora com a pandemia as pessoas ficam mais perto e no isolamento social aparece o covarde. Então o número de casos aumenta e automaticamente as mulheres também começam a denunciar mais. Nós precisamos interiorizar e criar uma rede de proteção no interior, o que não tem acontecido da forma que a gente gostaria”. (GAZETA DE ALAGOAS, 2020).
\end{abstract}

Diante deste fato, assim como nos demais dados trazidos para o artigo e revelados na pesquisa, o que nos chamou muito à atenção também foram as ações contínuas nos meses que antecederam ao mês de junho do corrente ano, quando mais de 100 (cem) medidas protetivas foram concedidas pela justiça. Calculando-se em média, mais de duas ações por dia durante período pandêmico do COVID-19.

Neste sentido, o artigo ainda questiona a eficiência do modelo jurídico atual de proteção aos direitos femininos, e ergue-se no intuito de preconizar caminhos que possam garantir o respeito a elas. Dessa Forma, indicando maneiras capazes de proteger a mulher contra os conflitos domésticos, assim como, do ciclo da violência doméstica para que seja minimizado. Sendo assim e desta forma, verificamos a eficácia da Lei 11.340/06 (Lei Maria da Penha) na prática dos lares em Maceió, podendo inclusive, elencar os apontamentos para tentar definir soluções que alterem esses atuais dados apresentados por meio do relatório da Secretaria de Estado de Segurança Pública (SSPAL).

\title{
CONSIDERAÇÕES FINAIS
}

Ressaltamos que o artigo está intrinsecamente ligado a investigação, as origens e causas da persistência do fenômeno violência, objetivando fornecer soluções adequadas de proteção a vítima, principalmente numa situação de isolamento social na Pandemia de Coronavírus. Isso porque, o isolamento social contribui para o aumento de casos de violência contra a mulher, e nesse sentido, é importante refletir da posição de 
vulnerabilidade social em que se encontra a mulher em termos de violência doméstica, numa lógica de heranças profundas do patriarcalismo, e das dificuldades de operacionalização da Lei Maria da Penha.

Consideramos também, que a realização da pesquisa é bastante oportuna, devido ao grande quantitativo de vítimas, pois traçar qual o perfil delas, quais são os fatores em elevam a violência doméstica, e que pode ter crescido por conta da pandemia (isolamento social), por se tratar da realidade diária enfrentada por uma parcela significativa das mulheres alagoanas, em especial as maceioenses, e de como isso impacta na realidade social. Dessa forma, as informações que foram coletadas irão contribuir para a academia a traçar meios dos quais irão construir soluções efetivas para o impasse e, consequentemente, permitir o empoderamento das mulheres dentro dos seus próprios lares.

Destacamos que ainda há a necessidade de tratar da temática da violência doméstica contra a mulher. Que inclusive, esta pauta seja fomentada também enquanto discussão de gênero, pois a Lei Maria da Penha foi estudada de forma multidisciplinar, para verificar como e de que forma o processo de violência contra a mulher pode atingir a finalidade de erradicar esse agravo social contra o gênero, e não transformar os sujeitos envolvidos em meros números e percentuais estatísticos sem se valer da dignidade humana dessas mulheres no ciclo da violência doméstica em Maceió, em tempos no COVID-19.

Por fim, e não menos importante neste artigo, os dados revelam que é urgente tratar de combater a violência contra a mulher, pois ela apresenta-se silenciosa e se torna perigosa, no sentido que as mulheres também sofrem violação psicológica, fruto consequente dos más tratos e dos consequentes transtornos psíquicos sociais. Sendo assim, segundo Stefle (2010) sobre os "agravos psicológicos na mulher, ele diz ser sorrateira, assume uma forma sistêmica e não parece maléfica”. Por isso, nunca devemos nos silenciar enquanto sociedade civil organizada, pois o povo que luta contra o modelo totalitário do Estado garante o direito constitucional a dignidade humana e combate à violência contra a mulher nestes tempos de Pandemia do Coronavírus 2019 em 2020. 


\section{AGRADECIMENTO}

O presente trabalho é fruto de uma pesquisa em andamento, com apoio da

Fundação de Amparo à Pesquisa do Estado de Alagoas (FAPEAL) e desenvolvido por estudantes voluntários do Grupo de Estudos da Ciência Conjunta Penal (GECCOPE/UNEAL).

\section{REFERÊNCIAS}

1. ALAGOAS, BO de violência doméstica pode ser registrado no Centro Especializado de Atendimento à Mulher. Secretaria da Mulher e dos Direitos Humanos do Estado de Alagoas, 2020. Disponível em <http://www.mulheredireitoshumanos.al.gov.br/noticia/item/2217-bo-deviolencia-domestica-pode-ser-registrado-no-centro-especializado-deatendimento-a-mulher>. Acesso em: 23 de agosto de 2020.

2. BARROSO, Luís Roberto. O direito constitucional e a efetividade de suas normas. Limites e possibilidades da Constituição brasileira. 8. ed. Rio de Janeiro: Renovar, 2009.

3. BRASIL. Constituição (1988). Constituição da República Federativa do Brasil de 1988. Brasília, DF: Presidência da República, 2020. Disponível em <http://www.senado.leg.br/atividade/const/con1988/CON1988_05.10.1988/in d.asp>. Acesso em 13 de maio de 2020.

4. BRASIL. Decreto-Lei 2.848, de 07 de dezembro de 1940. Código Penal. Diário Oficial da União, Rio de Janeiro, 31 dez. 1940.

5. BRASIL. Lei $n^{\circ}$. 11.340, de 7 de agosto de 2006. Lei Maria da Penha. Disponível em <http://www.planalto.gov.br/ccivil_03/_ato20042006/2006/lei/111340.htm> Acesso em 13 de maio de 2020.

6. CUNHA, Rogério Sanches. Manual de Direito Penal-Parte Geral, $8^{\text {a }}$ ed. Rev., amp Salvador: Editora JusPodivm, 2020.

7. FERNANDES, Maria da Penha M. Sobrevivi: posso contar. - $2^{\mathrm{a}}$ Reimp $2^{\text {a }}$. ed. Fortaleza: Armazém da Cultura, 2012.

8. GAZETA DE ALAGOAS, Pandemia eleva subnotificação da violência doméstica em Alagoas. Gazeta de Alagoas (coluna sobre a temática cidades), 2020 .

Disponível

em

<http://www.mulheredireitoshumanos.al.gov.br/noticia/item/22 17-bo-de- 
violencia-domestica-pode-ser-registrado-no-centro-especializado-deatendimento-a-mulher>. Acesso em: 23 de agosto de 2020.

9. GOMES, C. E.; LIMA, R. L.; CUNHA, M. S.; VASCONCELOS, M. R. Transições no mercado de trabalho brasileiro e os efeitos imediatos da crise econômica dos anos 2010. Economia e sociedade, v. 28, n. 2, p. 481-511, 2019.

10. LAPOUJADE, David. Fundar a violência: uma mitologia? In: NOVAES, Adauto (Org.). Mutações: fontes passionais da violência. São Paulo: Sesc, 2015.

11. LAVILLE, Christian; DIONNE, Jean. A construção do saber: manual de metodologia da pesquisa em ciências humanas. Porto Alegre: Artes Médicas; Belo Horizonte: Editora UFMG, 1999.

12. LERNER, Geda. A Criação Do Patriarcado: História da Opressão das Mulheres Pelos Homens.1.ed.São Paulo: Cultrix, 2019.

13. LIMA, Renato Brasileiro. Legislação Criminal Especial Comentada. $8^{\mathrm{a}}$ ed. Rev., amp. e atual. Salvador: Editora JusPodivm, 2020.

14. PORTO, Hermínio Alberto Marques; SILVA, Roberto Ferreira da. Fundamentação Constitucional das Normas de Direito Processual Penal: Bases Fundamentais para um Processo Penal Democrático e Eficiente. In: Tratado Luso-Brasileiro da Dignidade Humana. São Paulo: Quartier Latin, 2008.

15. SAFIOTTI, Heleieth.L.B.Gênero, Patriarcado e Violência.1.ed.São Paulo:Editora Fundação Perseu Abramo, 2011.

16. SILVA, Lilian Ponchio; SILVEIRA, Sebastião Sérgio da. A tutela penal diferenciada instituída pela Lei Maria da Penha e breve releitura de seu artigo 41. Revista da Faculdade de Direito da UFG, v. 33, n. 01, p. 18-25, jan.-jun. 2009.

17. ZIZEK, Slavoj. Violência: seis reflexões laterias. New York: Picador, 2008. 